\title{
Formulação e circulação dos sentidos de pandemia: o imaginário em primeiro plano
}

\author{
Ademir Antônio VERONEZE JR. (® \\ Universidade Federal do Rio de Janeiro (UFRJ)
}

Cláudio de Alencar PADUA @

OPEN ACCESS

Universidade Federal do Rio de Janeiro (UFRJ)

EDITADO POR

Raquel Freitag

AVALIADO POR

Cláudio de Alencar Padua Contribuiu com Ademir Antônio

\section{RESUMO}

Esta conferência de Eni Puccinelli Orlandi apresenta uma demonstração de análise discursiva acerca de textos coletados da mídia social Facebook relativos à pandemia de coronavírus, acontecimento atual que tem dominado as discursividades. Em torno de tal eixo, são abordadas questões como: a pertinência de estudar a circulação dos sentidos, além do modo como eles são formulados; a importância de levar em conta a relação entre a linguagem e a sociedade, explicitando, como exemplo, o modo como os sujeitos se relacionam com o político em discursos atravessados por teorias da conspiração; a distinção entre fantasia e imaginário e o papel deste último no aumento da volatilidade das interpretações e da diluição do real. Para tanto, são retomadas noções consolidadas no campo da Análise de Discurso - inclusive algumas das que foram desenvolvidas na obra da própria autora, como a paráfrase e a polissemia, o silêncio, entre outras.

\section{RÉSUMÉ}

Dans cette conférence, Eni Puccinelli Orlandi nous offre un exemple d'analyse discursive des textes collectés sur le réseau social Facebook liés à la pandémie du Covid-19, celui-ci est un événement de l'actualité qui est mis en évidence dans les discursivités. Autour de cet axe, des questions sont traitées, en ce qui concernent : la pertinence d'étudier la circulation des sens et la façon dont ils sont formulés ; l'importance de tenir en compte la 


\section{REVISTA DA ABRALIN}

relation entre la langue et la société afin d'expliquer, par exemple, comment les sujets traversés par les théories du complot se rapportent aux relationspolitiques dans le discours; la distinction entre la fantaisie et l'imaginaire et le rôle que celui-ci joue dans l'augmentation de la volatilité des interprétations et dans la dilution du réel. À ce propos, on reprend des notions consolidées dans le domaine de l'analyse du discours, parmi lesquelles on peut trouver quelques-unes développées par l'auteur elle-même, dont le travail a apporté les études de la paraphrase et la polysémie, du silence et parmi d' autres.

PALAVRAS-CHAVE

Imaginário. Pandemia. Volatilidade das interpretações.

MOTS-CLÉS

Imaginaire. Pandémie. Volatilité des interprétations.

Desde que topou com a pandemia do coronavírus, a comunidade científica mundial lida com restrições de diversas atividades. Nesse cenário, conferências online de pesquisadores renomados, como as organizadas pela Associação Brasileira de Linguística (Abralin) se comparam a oásis no deserto. A fala de Eni Puccinelli Orlandi foi recebida pelos seus interlocutores como uma fonte de resiliência e de instrumentos teórico-metodológicos para o desenvolvimento do campo de estudos da Análise de Discurso (AD). Manifestando estranhamento com a modalidade virtual posto que está habituada à interação presencial, ela encorajou sua audiência a se fazer presente na ocasião - pelas conversas ali estabelecidas - e no mundo, pelo trabalho científico possível de ser realizado nas atuais condições.

Orlandi também abordou interatividade, bem como rede de informação, enquanto noções atinentes à circulação de sentidos, tema que constituiu o cerne de sua apresentação. Ressaltou que os analistas de discurso devem pensar não só em como os sentidos são formulados, mas também em como eles circulam. Considerando a pandemia como um acontecimento que tem dominado as discursividades, deu exemplos de palavras e sentidos contaminados, por assim dizer. Um deles é o sentido da palavra casa, agora significando majoritariamente abrigo, lugar seguro. Outro exemplo é o uso de isolamento social - às vezes reclinado como distanciamento social. Cabe questionar o que vem a ser isolamento social: não é a situação em que vive a maioria da população em suas "comunidades"? A autora concebe tais exemplos como processos de metaforização, partindo do princípio de que os sentidos não estão nas palavras, mas nas relações que se instauram entre elas, pois conversam umas com as outras produzindo transferências de sentidos e equívocos. Assim, explica ela, "nossas palavras se encharcam de sentidos de pandemia". 


\section{REVISTA DA ABRALIN}

A conferencista delineou um quadro de guerra de informação e de campanhas de desinformação, o qual produz emoções que ligam os sujeitos às telas e às redes. Mas não resulta apenas nisso. Intensifica-se o funcionamento do imaginário acerca da discursividade atual, desencadeando gestos de interpretação que metaforizam acontecimentos reais como a pandemia. No entanto, para além da multiplicidade de versões dos textos em circulação - derivados da tensão entre processos parafrásticos e polissêmicos, ou seja, entre a repetição do mesmo e a ruptura que inaugura novos sentidos -, Orlandi chama atenção para a diluição do real por meio dos efeitos da volatilidade das interpretações. Para aclarar a questão, demonstrou a análise de dois textos relativos à pandemia, ambos coletados da mídia social Facebook, nos quais ela identifica um tema em comum: a conspiração.

O primeiro foi escrito por Malu Aires, publicamente conhecida no campo artístico como compositora e intérprete. Assim começa o texto: "Bolsonaro esconde sua doença desde o início de 2018". Soando como título, a afirmação se desdobra com conjecturas sobre um Brasil esmorecido em um futuro próximo, causado pela pandemia, ou por repercussão política, supondo adoecimento - encoberto - e morte de Bolsonaro. "Era preciso que o genocida não fosse diagnosticado com doença grave que prejudicasse sua candidatura", narra. Esta e cada formulação de "genocida", destaca Orlandi, traz o sentido de pandemia, entre outros. Na narrativa, Bolsonaro escondeu a doença até que surgiu a "fakada". A analista aponta que o uso da letra "K" para descrever e nomear o fato produz o efeito de negálo - pela associação com a palavra "fake" - no mesmo instante da interpretação. Outro destaque nesse primeiro movimento de análise é a observação de que uma teoria de conspiração é colocada em prática, constituindo no texto um aspecto semelhante ao do boato quanto à circulação: a necessidade de um gatilho social, isto é, o funcionamento condicionado ao espalhamento, à viralização.

Prosseguindo ao segundo material analisado, um vídeo acessado a partir de outra postagem no Facebook e protagonizado por Maria Homem, que fala a partir de sua posição-sujeito psicanalista. Ela não conspira, mas se refere a teorias do tipo - e o modo como ela o faz é justamente o que Orlandi sublinhou. Apoiando-se no pressuposto de que, ao imaginar, o sujeito se dirige mais para fantasia, os dizeres no vídeo repetidamente se iniciam da mesma maneira - "Imagina que" -, na tentativa de levar quem assiste a imaginar algo que não estava sendo dito, mas que está sugerido. Aí reside, inclusive, o silêncio - outra noção abordada por Orlandi em estudos passados - também significando. As palavras chinês e China preencheriam a lacuna de identificação de vilões na narrativa da conspiração segundo a qual o coronavírus é chinês e foi propagado intencionalmente por aquele país. Em seguida, a psicanalista profere um conceito de conspiração e seu ponto de vista sobre o assunto: sendo o sujeito incapaz de suportar o acaso e o aleatório, ele prefere imaginar, fantasiar, uma mão poderosa a que ele possa responsabilizar. Então, enquanto as interpretações com viés conspiratório no vídeo se assentam em fantasias, no primeiro texto elas se apoiam em supostas verdades.

É neste ponto que Orlandi fez convergirem as considerações iniciais e os comentários analíticos em uma consistente distinção sobre a noção de imaginário na $\mathrm{AD}$ em meio a outros entendimentos, como o de fantasia - enquanto devaneio, espaço de fuga da realidade, assumindo um sentido negativo para a Psicologia em geral; ou revestindo de sentido positivo, enquanto espaço a ser explorado para a criação artística e para o retorno à realidade em um contexto de tratamento, de acordo com 


\section{REVISTA DA ABRALIN}

Sigmund Freud. Em contrapartida, na AD compreende-se imaginário como prática inerente, constitutiva do sujeito, compreendendo a impossibilidade de significar sem imaginar. O sujeito projeta imagens de si, dos outros e daquilo sobre o que ele fala. No caso do primeiro texto analisado, por exemplo, Orlandi observou que o que domina a relação do sujeito com o político são as imagens feitas do presidente, da doença dele, da facada e das eleições.

A produção de imagens se dá por meio da ideologia, da relação não consciente que os sujeitos mantêm com a língua e com a história. Ou seja, essas imagens são constituídas com base nos efeitos de evidência produzidos por um dispositivo ideológico presente em todos os sujeitos. A saber: 1) o efeito de transparência, em que o sentido aparece como estando já lá - logo, para o sujeito, aquilo que ele diz só podia ser aquilo e não outra coisa; e 2) o efeito no qual o sujeito se pensa como origem do dizer, sem se dar conta que as tomadas de palavras se sustentam na base do dizível, do já-dito. Aqui se pode falar, portanto, em dupla ilusão. Por conseguinte, entram em jogo processos em que os sujeitos se identificam com certos sentidos e se descolam deles também.

Das ilusões e das identificações resultam as convicções, que ora são amplamente difundidas em argumentações de todo tipo. Recorrendo a Friedrich Nietzsche, que credita às convicções o status de inimigas da verdade, sendo mais perigosas do que a mentira, Orlandi adverte que elas se tratam de armadilhas e enfatiza que os sentidos não são únicos nem fixos. Esse alerta tangencia, claro, a questão da diluição do real ${ }^{1} \mathrm{e}$ da evanescência dos fatos devido aos efeitos da volatilidade das interpretações, com forte presença do imaginário nas argumentações atualmente, ou seja, com a sobreposição do fato pelas imagens que se fazem deste. É o caso de interpretações que levam à suspeita, comuns em textos com o tema da conspiração. Por fim, ao concluir sua explanação, Orlandi assinalou que seu estudo e os diálogos possíveis no evento proporcionaram a compreensão das formas como, nessa conjuntura capitalista da pandemia e com os processos de significação por ela explicitados, o homem interroga o sentido de sua humanidade e de sua busca de liberdade.

\section{REFERÊNCIAS}

FREUD, Sigmund. Projeto para uma psicologia científica. Ed. standard brasileira das obras psicológicas completas de Sigmund Freud. Tradução de J. Salomão. Rio de Janeiro: Imago, 1996. v. 1.

GADET, Françoise; PÊCHEUX, Michel. A língua inatingível - O discurso na história da Linguística. Tradução de B. Mariani et M. E. C. de Mello. Campinas: Pontes Editores, 2004.

NIETZSCHE, Friedrich. Humano, demasiado humano. Tradução de P. C. de Souza. São Paulo: Companhia das Letras, 2005.

VOLATILIDADE da interpretação: política, imaginário e fantasia. Conferência apresentada por Eni Puccinelli Orlandi [s.l., s.n], 2020. 1 vídeo (1h 55min 08s). Publicado pelo canal da Associação Brasileira de Linguística. Disponível em: https://www.youtube.com/watch?v=MjCsJxfiXtg\&t=1520s. Acesso em: 25 mai 2020.

1 Noção que, nas palavras de Pêcheux, corresponde ao "impossível que não seja assim". Conforme explicou Orlandi, o sujeito não descobre o real, mas "topa" com ele. 